\title{
SSinteza
}

Impact of Internet on Business Activities in Serbia and Worldwide

Uticaj Interneta na poslovanje u Srbiji i svetu

DOI: 10.15308/SINTEZA-2014-429-432

\section{E-LEARNING SISTEM ZA GRAFIČKU TEHNOLOGIJU VŠSS BEOGRADSKA POLITEHNIKA}

\author{
Srđan Trajković, Dominik Brkić, Duško Radaković \\ všss Beogradska politehnika, Srbija
}

\begin{abstract}
:
U radu se predstavlja E-learning sistem za predmete grafičke tehnologije VŠSS Beogradska politehnika. Ovaj sistem je još u razvoju i planira se njegova implementacija u nastavni proces. Cilj rada je da sagledaju pozitivne i negativne strane ovakvih sistema. Takođe želimo da prikažemo i osmišljeni vid komunikacije putem Interneta. Kroz ovaj rad želimo da ukažemo i na određene mogućnosti materijalnih i resursnih ušteda u obrazovanju. U radu se uporedno prikazuju rezultati studenata uzorkovane grupe korisnika kao i studenata koji su nastavu pratili klasičnim putem, čime se dokazuje opravdanost uvođenja ovakvog sistema edukacije.
\end{abstract}

\author{
Key words: \\ E-Learning, \\ DLS, \\ obrazovanje, \\ edukacija.
}

\section{UVOD}

Ubrzani razvoj informatičko komunikacione tehnologije (ICT) uslovio je i raznolikost njene primene u svim sferama današnjeg života. Jedna od oblasti o kojoj svako razvijeno društvo vodi računa je obrazovanje. Primena ICT-ija u ovoj sferi počela je još pre više od 30 godina. Pre svega korišćenjem računara kao računskog sredstva a kasnije kroz kreiranje baza podataka za praćenje elemenata obrazovnog procesa pa sve do razvoja virtuelnih sistema edukacije i DLS sistema. Naročito je razvoj ICT-a u pracu multimedija i brze i jeftine komunikacije uticao na njegovu sve veću primenu u odbrazovanju.

Razvojem savremenih sistema edukacije ostvaruje se više različitih ciljeva.

\section{TRENUTNO STANJE PRIMENE ICT-A U VŠSS BEOGRADSKA POLITEHNIKA}

VŠSS Beogradska politehnika kao jedan od subjekata u procesu obrazovanja, a dosta visoko kotiran u grupi Visokih škola strukovnih studija, takođe čini napore u pravcu poboljšanja svog obrazovnog procesa. Jedan od pravaca razvoja je i uvođenje savremenijih metoda u obrazovni proces korišćenjem ICT-a.
Razvojem svog informacionog sistema VŠSS Beogradska politehnika je prvo uvela još devedestih godina računarsku opremu u nastavu. Nakon toga se razvio komunikacioni sistem sa studentima i predavačima putem kreiranja Web sajta Škole a i sistem E-mail i SMS komunikacije. Faza koja prati ovu je uvođenje Moodle-a kao deo DLS-a (Distance Learning System).

U sklopu korišćenja Moodle-a nisu uvedeni svi predmeti već samo pojedini. Tu smo se sreli sa prvim problemom E-learning-a i DLS-a.

\section{PROBLEMI PRIMENE DLS I E-LEARNING-A}

Jedan deo predavača, naročito onih sa većim iskustvom, nije bio dovoljno informatički potkovan da bi mogao da se jednostavno uključi u ovakav vid rada sa studentima. Tu se misli ne samo na nedovoljno znanje iz oblasti DLS-a već i iz osnovnih kompjuterskih programa. Aktivnim edukacijama i podmlađivanjem kadra došlo se do dovoljno dobrih kadrova da se ovakav rad ipak može dalje sprovesti.

Takođe postoji i problem sa prethodnim znanjem studenata koji se uključuju u ovakav vid obrazovnog procesa. Dobar deo studenata nema dovoljno znanja iz ovih oblasti (što se naročito primećuje kod dece iz manjih i ruralnih sredina). Međutim savremena komunikacija putem društvenih 
mreža, Web-a uopšte i mobilne telefonije dosta su dobar osnov na kome studenti brzo prihvataju nove tehnologije.

Jedan od problema je stanje komunikacione mreže. Tu se pre svega misli na stanje ADSL usluga putem klasične telefonije. Iako sada postoje paketi sa brzim i velikim protokom, zbog zastarelosti centrala i žičanih vodova maksimalna brzina nije uvek dostupna, pa se mogu dešavati zastoji u komunikaciji (pad brzine interneta - veoma je čest u našem okruženju)

Ali najveći problem uvođenja i eksploatacije ovakvih sistema, u ovom trenutku, je novac. Neophodno je kupiti dobru računarsku i komunikacionu opremu, investirati u razvoj aplikacija, obrazovanje kadrova i uvođenje novih kadrova u institucije obrazovanja. Ovde mislimo na probleme odobravanje novih radnih mesta od strane ministarstava. VŠSS Beogradska politehnika već duži period pokušava da otvori radna mesta sistem administratora i Web administratora ali ne nailazi na razumevanje ministarstava

\section{PREDNOSTI I UŠTEDE U PRIMENI DLS I E-LEARNING-A}

Bez obzira na navedene probleme uvođenja i primene DLS-a i E-learning-a stvara i višestruke koristi i prednosti ustanovama koje su se odlučile za njihovu primenu.

Praćenje nastave sa bilo koje lokacije omogućuje ustanovi da u relativno skromnim prostornim uslovima može da edukuje veći broj zainteresovanih korisnika. To takođe omogućava i veliku materijalnu uštedu i instituciji jer održava manji prostor a i studentima štedi troškove prevoza, putovanja i boravka u mestu gde se nastava fizički održava.

Mogućnost praćenja nastave u realnom vremenu ali i sa odloženim vremenskim pristupom je jedna od prednosti. To znači da student koji nije bio u mogućnosti da u realnom vremenu prati nastavu može da je odsluša i kasnije a da ne izgubi termin zbog ne prisustva.

Moćnost organizovanja praktične nastave uz pomoć savremenih video uređaja je jedana od prednosti ovakvih sistema.

Dostupnost predavača i studenata praktično u svakom trenutku za konsultacije ili neku drugu vrstu saradnje je isto od velikog značaja u primeni DLS-a i E-learning-a.

Međusobna saradnja obrazovnih ustanova u razmeni predavača i predavanja kao i konsultacija je još jedna od prednosti koja se nameće u primeni ovih sistema.

\section{RAZVOJ E-LEARNING SISTEMA ZA SMER}

\section{Grafičke tehnologije u Všss Beogradska politehnika}

Nakon što smo ustanovili da se korišćenjem Moodle-a na određenim predmetima, ne gubi na kvalitetu postignutog nivoa znanja studenata odlučili smo da se upustimo $u$ razvoj E-learning sistema za smer Grafičke tehnologije u VŠSS Beogradska politehnika. (tabelarni prikaz studenata na predmetu Hemija klasična i nastava na Moodle-u)
Tabela 1 - tabelarni prikaz broja studenata i prolaznost na kolokvijumima u zavisnosti od načina praćenja nastave

\begin{tabular}{|c|c|c|c|c|}
\hline $\begin{array}{c}\text { godina } \\
\text { slušanja }\end{array}$ & $\begin{array}{c}\text { broj stude- } \\
\text { nata - } \\
\text { klasična } \\
\text { nastava }\end{array}$ & $\begin{array}{c}\text { broj stude- } \\
\text { nata - } \\
\text { DLS nastava }\end{array}$ & $\begin{array}{c}\text { prolaznost na } \\
\text { kolokvijumima } \\
\text { klasične studije }\end{array}$ & $\begin{array}{c}\text { prolaznost } \\
\text { na kolokvi- } \\
\text { jumima DLS } \\
\text { studije }\end{array}$ \\
\hline 2008 & 36 & 24 & $53 \%$ & $42 \%$ \\
\hline 2009 & 30 & 32 & $53 \%$ & $47 \%$ \\
\hline 2010 & 26 & 29 & $42 \%$ & $52 \%$ \\
\hline 2011 & 30 & 22 & $70 \%$ & $68 \%$ \\
\hline 2012 & 26 & 32 & $73 \%$ & $75 \%$ \\
\hline
\end{tabular}

Za ovaj smer smo se odlučili iz više razloga. Pre svih tu imamo najmlađi i najedukovaniji kadar za primenu ovakvog sistema edukacije. Studenti sa ovog smera su najrazuđeniji po mestu stanovanja, a takođe za ovaj smer imamo najviše razvijenog pratećeg materijala.

Takođe smo izvršili anketu među studentima u pravcu želje da se uključe u razvoj ovakve platforme. Sa smerova za Grafičku tehnologiju i sa smerova za Dizajn je bio najbolji odziv. Više od 50\% studenata je želelo da se uključi u ovaj ekperimentalni rad. Što smatramo značajnim za donošenje odluke o upuštanju u jedan ovakav projekat.

Razvija se model kojem će se pristupati i komunicirati u Web okruženju. Dovoljno je da korisnik ima pristup Internetu i bilo koji komunikacioni uređaj sa kamerom (računar, laptop, tablet ili smartphone).

Predviđeno je da celim radom i komunikacijom upravlja administrator sistema a da na samim predavanjima ili konsultacijama radom rukovode predavači. U svakom trenutku se aktiviranjem određenih komandi mogu u komunikaciju uključiti i ostali učesnici sesije.

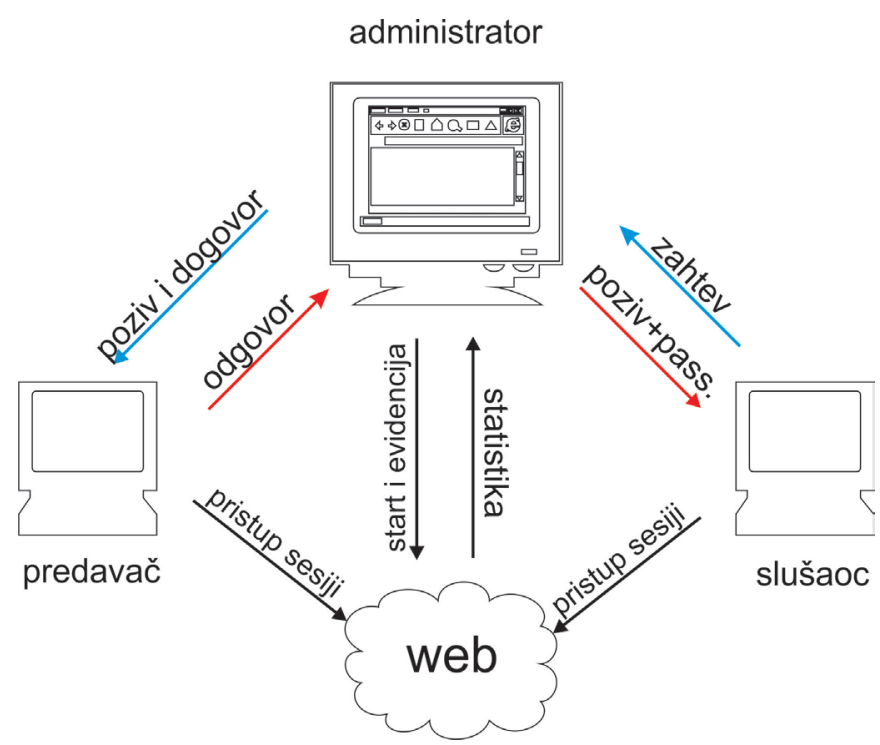

Slika 1. - Šema komunikacije među učesnicima E-learning sistema

Administrator rukovodi sistemom tako što objavljuje termine održavanja nastave za određene predmete, na koje se slušaoci prijavljuju. $\mathrm{Na}$ osnovu prijavljenih slušalaca kreira se baza iz koje administrator u određenom 
trenutku šalje poziv za pristup predavanju i lozinku koja to slušaocu omogućava. Svi studenti VŠSS Beogradska politehnika koji su upisali određeni predmet automatski se postavljaju na listu poziva za taj predmet.

Osim slušalaca administrator u nastavu uključuje i poziva i predavače. Svi predavači VŠSS Beogradska politehnika su automatski priključeni ovim listama poziva dok se spoljni predavači dodaju na osnovu ostvarenih dogovora i postignutih ugovornih obaveza.

Svim predavačima se šalju i pozivi za prisustvo na tudim predavanjima pa se oni na njih mogu prijaviti kao slušaoci.

\section{BEOGRADSKA POLITEHNIKA - GRAFIČKA TEHNOLOGIJA}

त home

居 katalog individualne krupne ${ }_{\text {knsultacije }}^{\text {preuzm }}$

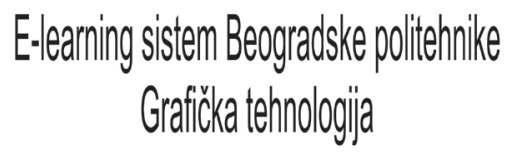

\begin{tabular}{|l|l|l|}
\hline \multicolumn{2}{|c}{3.} \\
\hline prijava & ime i prezime: & status: Student \\
\hline \multicolumn{2}{l}{ E-mail } & tel: \\
\hline
\end{tabular}

Slika 2. - Početna strana web aplikacije E-learning sistema

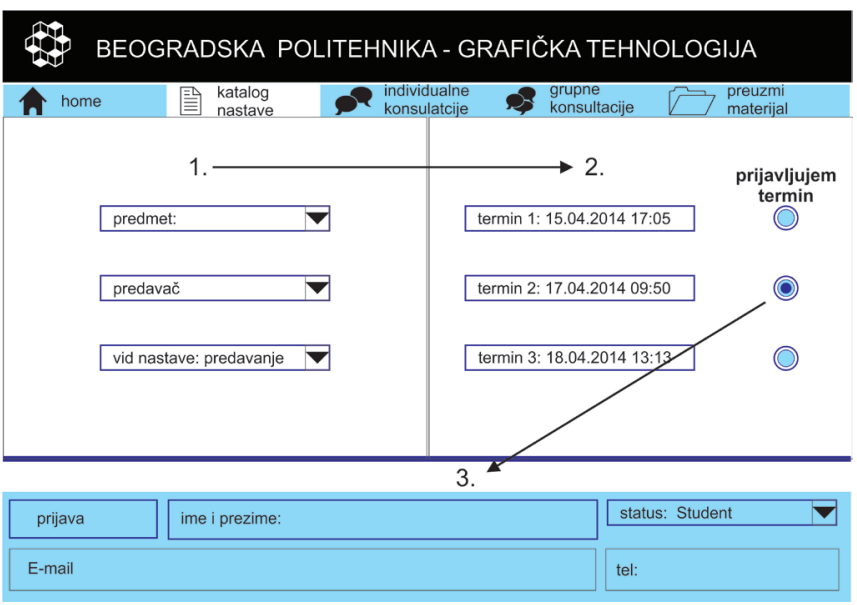

Slika3. - Prikaz ekrana na kome se slušaoci prijavljuju za slušanje nastave

U svakom trenutku se na ekranu administratora i predavača vidi ko je sve prisutan na predavanju i kojoj kategoriji slušalaca pripada.

Zamišljno je da tokom predavanja mogu da se dele (šeruju) ekrani predavača kao i video putem web kamere koju je poželjno imati.

Svi učesnici se autentifikuju imenom (user name) i lozinkom (password) a tamo gde je moguće i slikom (ili videom). Određeni korisnici kao što su administratori za prateće službe i administrator celog sistema autentifikuju se i identifikuju i smart karticama

U toku predavanja ukoliko postoji potreba za pitanjem ili pojašnjenjem slušalac se klikom na određenu ikonicu može prijaviti i predavač je dužan da ga u trenutku kada mu to pogoduje uključi u komunikaciju.
Predviđeno je da se sva predavanja snimaju i da se na E-mail adrese prijavljenih slušalaca dostave ali i postave na lokaciju gde bi bila svima dostupna. Takođe vodi se evidencija preuzetih predavanja kako bi predavač znao ko je sve preuzeo njegova predavanja i tako zaštitio i svoja autorska prava.

BEOGRADSKA POLITEHNIKA - GRAFIČKA TEHNOLOGIJA

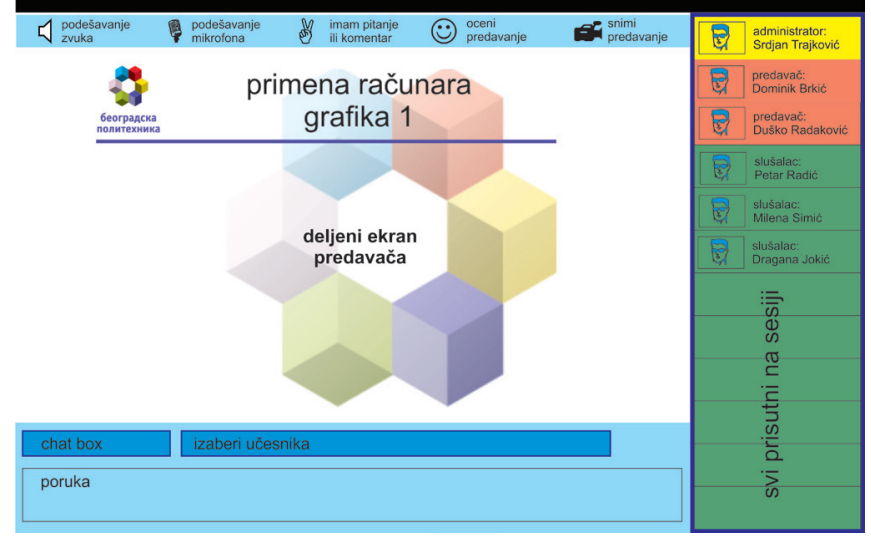

Slika 4. - Ekran administratora i predavača za vreme sesije deljen ekran predavača i spisak svih prisutnih slušalaca

U slučaju konsultacija proces je malo drugačiji. Predavači imaju unapred zakazane termine konsultacija i student se prijavljuje administratoru da želi da komunicira sa predavačem. Nakon toga dobija poziv i lozinku za autentifikaciju i identifikaciju za pristup komunikaciji u tom terminu. Slušalac (najčešće student) može da pošalje zahtev administratoru za konsultacije sa nekim od predavača i van zakazanog termina. U dogovoru sa predavačem administrator utvrđuje mogući termin i šalje slušaocu poziv sa terminom i lozinkom za njegov pristup. Konsultacije mogu biti i grupne i pojedinačne.

\section{REALIZACIJA E-LEARNING SISTEMA}

Razvijeni sistem je još u eksperimentalnoj fazi i koristimo ga unutar naše interne mreže. Za sada nema nekih većih problema u komunikaciji osim sa streaming-om odnosno direktnim video prenosom. Ovo je problem brzine same mreže i prevelikog broja korisnika u njoj. U sledećoj fazi testiranja odvojićemo posebnu podmrežu za ovaj projekat.

Dosadašnja testiranja su dala i pozitivan odziv studenata na ovakav vid komunikacije i sa nestrpljenjem očekuju da se sistem konačno pusti u funkciju. Nadamo se da će to biti početkom naredne školske godine.

\section{ZAKLJUČAK}

$\mathrm{Na}$ ideju da kreiramo sopstveni E-learning sistem smo došli nakon analize funkcionisanja sličnih Škola u Evropi i Americi kao i u okruženju. Svaka ozbiljna obrazovna ustanova ima ovakav sistem bez obzira da li sama razvija softver ili koristi neki komercijalni. To je samo još jedan od dokaza da se ovakvi sistemi isplate i to ne samo kao edukativni već i kao odraz ustanove i njene želje da napreduje i dokaže se u okruženju. 
Smatramo da ćemo implementacijom svog sistema i mi biti u mogućnosti da pokažemo okruženju koliko smo ozbiljna ustanova a u perspektivi ćemo raditi na tome da se ovaj sistem proširi i na sve ostale smerove pa čak ako bude zainteresovanih Škola i na neke od njihovih smerova.

Smatramo da će samo ovakav pristup edukaciji i obrazovnim sistemima dati rezultate u budućnosti i da će omogućiti školovanje većem broju ljudi.

\section{LITERATURA}

[1] Margued Iskander, "Innovative Techniques in Instruction Technology, E-learning, E-assessment and education", Springer, 2008
[2] Badrul Kahn, "Managing E-learning strategies”, Information Science publishing, 2005

[3] Harald Kjellin and Terese Stenfors, “Acquiring the most Relevant Knowledge for an Elearning System”, The European Conference on E-Learning, Brunel University, Uxbridge, pp 185-192, 2002

[4] www.adobe.com

[5] www.co-su.com

[6] www.bestelearningplatforms.com 